\title{
Comparison of screening tests of asymptomatic bacteriuria in pregnancy in a Tertiary Care Hospital, Solapur
}

\author{
Prakash H. Waghmare ${ }^{1}$, Shalaka S. Rudrakshi ${ }^{2, *}$, Kishor V. Ingole ${ }^{3}$, Rashmi S. Bawane ${ }^{4}$, Sadiya V. Shaikh ${ }^{5}$ \\ ${ }^{\mathbf{1}}$ Associate Professor, ${ }^{2} \mathrm{MBBS}$ Student, ${ }^{3}$ Professor \& HOD, ${ }^{\mathbf{4}}$ Assistant Professor, ${ }^{5}$ Junior Resident, Dept. of Microbiology, Dr. V. \\ M. Government Medical College, Solapur, Maharashtra, India
}

*Corresponding Author:

Email: shalakarudrakshi@ymail.com

\begin{abstract}
Asymptomatic bacteriuria leading to urinary tract infection is the most frequently encountered condition in pregnancy, which has been associated with an increased risk of pre-term delivery and low birth weight.

Clinically the diagnosis of UTI can be difficult as symptoms are non-specific. Gold standard method for diagnosis of UTI is urine culture. Up to 18 hours are required for bacterial growth on culture media by standard laboratory techniques, which leads to delay in the treatment.

In the present study 100 midstream urine samples from asymptomatic pregnant women were collected. Gram staining, Griess Nitrite Test, Triphenyl tetrazolium chloride test (TTC), Catalase test, these four screening tests were performed on the samples and their results were compared with the results of urine culture.

Among these 100 samples, the study revealed that 14 pregnant women had significant bacteriuria $(1,00,000$ or more bacteria/ ml of urine) giving a prevalence of $14 \%$.

This study showed that Gram staining has highest sensitivity i.e. $92.85 \%$ and TTC has highest specificity i.e. $98.83 \%$ for the detection of significant bacteriuria. To conclude if we perform these two tests in combination then we get a sensitivity of $98.97 \%$ and specificity of $94.22 \%$ which is not $100 \%$ but very close to it. Use of these screening tests will help in early diagnosis and initiation of treatment of UTI in pregnant women.
\end{abstract}

Keywords: Asymptomatic bacteriuria, Pregnancy, Screening tests, UTI.

\section{Introduction}

Asymptomatic bacteriuria leading to frank Urinary tract infection (UTI) is one of the most frequently encountered condition in pregnancy. ${ }^{1}$ During pregnancy, urethral compression at the pelvic brim by the enlarging uterus leads to stasis of urine, incomplete emptying and residual urine, which is one of the most important factors that can initiate the proliferation of microorganisms. Both progesterone and oestrogens levels increase during pregnancy and these will lead to decreased ureteral and bladder tone. All these factors cause urinary stasis and uretero-vesical reflux. Glycosuria in pregnancy is also another well-known factor which predisposes pregnant women to UTI.

Patients with UTI present with classical symptomatology of frequency, urgency, urinary tenesmus, and fever or it may be completely without any symptoms (asymptomatic bacteriuria). ${ }^{2}$ Asymptomatic bacteriuria is defined as more than 100,000 colonies of a single bacterial species per $\mathrm{mL}$ of urine, cultured from midstream sample of asymptomatic women. It is present in 2 to 7 percent of pregnant women. ${ }^{3}$

Without treatment, asymptomatic bacteriuria in pregnancy is associated with preterm delivery, intrauterine growth retardation, low birth weight, maternal hypertension, preeclampsia and anaemia. UTI triggers the production of prostaglandins E2 and F2a; these prostaglandins are known to stimulate uterine contractions. ${ }^{4}$ Thus, UTI is associated with preterm labour. Acute pyelonephritis can lead to maternal sepsis.
In addition, if untreated, $20-40 \%$ of pregnant women with asymptomatic bacteriuria may develop pyelonephritis later in pregnancy ${ }^{[5]}$.Acute pyelonephritis can lead to maternal sepsis.

Clinically the diagnosis of UTI can be difficult as symptoms are non-specific. The only way to reliably exclude a urinary tract infection is by the laboratory examination of a urine specimen. Many prompt diagnostic methods like gram staining, Griess Nitrite test, TTC and Catalase test are available. These rapid diagnostic tests can rule out urine infection. They are less time-consuming, less expensive and are useful in small laboratories having no culture facility. They are also more rapid than culture in diagnosing complicated and uncomplicated UTI. But gold standard method for diagnosis of UTI is urine culture. ${ }^{6}$ Up to 18 hours are required for bacterial growth on culture media by standard laboratory techniques, ${ }^{7}$ which means that the condition remains undiagnosed for the first 24-48 hours after presentation, which leads to delay in the treatment.

The detection of bacteriuria allows an approach to be made to avoid complications in pregnancy at an early stage. Antibiotic treatment for asymptomatic bacteriuria (ASB) is indicated in pregnant women to reduce the risk of complications. Positive screening tests will aid to start antibiotic treatment earlier than after culture report. With this in mind an attempt was made to analyse the screening tests with culture. In this cross-sectional study midstream urine samples were collected from the Antenatal women visiting tertiary care hospital and they 
were screened for urinary tract infection by using rapid screening tests such as gram staining, Griess nitrite, TTC, catalase and then urine culture was done on blood agar and MacConkey agar. By considering the culture as gold standard the results of these screening tests were compared with it to detect their sensitivity and specificity.

\section{Materials and Methods}

It is a retrospective cross-sectional study. It was carried out in the department of Microbiology, Dr. V.M.G.M.C., Solapur. A total of 100 mid-stream urine samples were collected from asymptomatic pregnant women of varying ages attending tertiary care hospital over a period of 2 months. Patients from varying gravida and all three trimesters were included.

Following procedures were followed.

1. Collection of urine: Patients were instructed to collect midstream urine sample with all aseptic precautions in sterile urine container.

2. Microscopic examination of urine: Wet mount was performed to visualise the pus cells and to rule out contamination. A drop of uncentrifuged urine was allowed to air dry. The smear was Gram stained and examined under oil immersion. Twenty fields were examined. Presence of at least one organism per field was considered as significant $\left(10^{5} / \mathrm{ml}\right.$ organisms). ${ }^{8}$

3. Screening tests:

i. Griess Nitrite Test: $1 \mathrm{ml}$ of urine was taken in a clean sterile test-tube. One $\mathrm{ml}$ of $10 \%$ potassium nitrate was added and incubated at $37^{\circ} \mathrm{C}$ for two hours. To this one $\mathrm{ml}$ of Griess nitrite reagent was added i.e., solution-A: Sulphanilic acid and solution-B: $\alpha-$ naphthylamine. Development of pink to dark red colour indicates a positive test. ${ }^{9}$

ii. Triphenyl tetrazolium chloride test (TTC): 2 $\mathrm{ml}$ of urine was taken in a sterile test tube and $0.5 \mathrm{ml}$ of working triphenyl tetrazolium chloride reagent was added. This mixture was incubated at $37^{\circ} \mathrm{C}$ for four hours. Formation of red precipitate indicates a positive test. ${ }^{10}$

iii. Catalase test: $3 \%$ Hydrogen peroxide was added to $1.5-2 \mathrm{ml}$ of urine, and the solution was mixed gently. The formation of bubbles was interpreted as a positive test. ${ }^{11}$

\section{Semi-quantitative culture:}

Standard loop technique: Semi-quantitative culture of urine was done by standard loop technique on Blood agar and MacConkey's agar.

A calibrated wire of $0.001 \mathrm{ml}$ capacity inoculating loop was flamed and allowed to cool without touching any surface.

The urine was thoroughly mixed and the top of the container was removed.

The loop was inserted vertically into the urine to allow urine to adhere to the loop.

The loopful of urine was spread without flaming or re-entering urine; loop was drawn across the entire plate, crossing the first inoculum numerous times for producing isolated colonies. The central streak was the first inoculum.

Plates were incubated for at least 18-24 hours at $37^{\circ} \mathrm{C}$. Colonies were counted on each plate.

Diagnostic measures such as sensitivity and specificity of Gram staining, Griess nitrite test, Triphenyl tetrazolium chloride test and Catalase test will be calculated by standard formulas using culture as gold standard.

Sensitivity and specificity were calculated by following formulas.

Table 1

Sensitivity $=a /(a+c) \times 100$

\begin{tabular}{|l|c|c|c|}
\hline \multicolumn{1}{|c|}{\begin{tabular}{c} 
Screening test \\
\multicolumn{1}{c|}{ results }
\end{tabular}} & \multicolumn{2}{c|}{ Diagnosis } & \multirow{2}{*}{ Total } \\
\cline { 2 - 3 } & Diseased & Not diseased & $\mathrm{a}+\mathrm{b}$ \\
\hline Positive & $\mathrm{a}($ True-positive $)$ & $\mathrm{b}$ (False-positive) & $\mathrm{c}+\mathrm{d}$ \\
\hline Negative & $\mathrm{c}$ (False-negative) & $\mathrm{d}$ (True-negative) & $\mathrm{a}+\mathrm{b}+\mathrm{c}+\mathrm{d}$ \\
\hline Total & $\mathrm{a}+\mathrm{c}$ & $\mathrm{b}+\mathrm{d}$ & \\
\hline
\end{tabular}

Specificity $=d /(b+d) \times 100$

Formula for combined sensitivity and specificity of two tests: When two tests A and B are combined in such a way that if any of those test is positive then the result is considered positive then Sensitivity $(A+B)=[S e n s i t i v i t y(A)+$ Sensitivity (B)]- [Sensitivity (A) x Sensitivity (B)] Specificity $(A+B)=(\operatorname{Specificity~A~x~Specificity~B)~}$

\section{Results}

Out of the 100 urine samples collected from pregnant women attending the antenatal clinics, every sample was subjected to screening tests including microscopic examination. Among these 100 samples, the present study revealed that 14 pregnant women had significant bacteriuria $(1,00,000$ or more bacteria/ $\mathrm{ml}$ of urine) .

Age wise distribution in pregnant women with bacteriuria is shown in (Fig. 1). It shows that the incidence of bacteriuria increases with age among the pregnant women. 


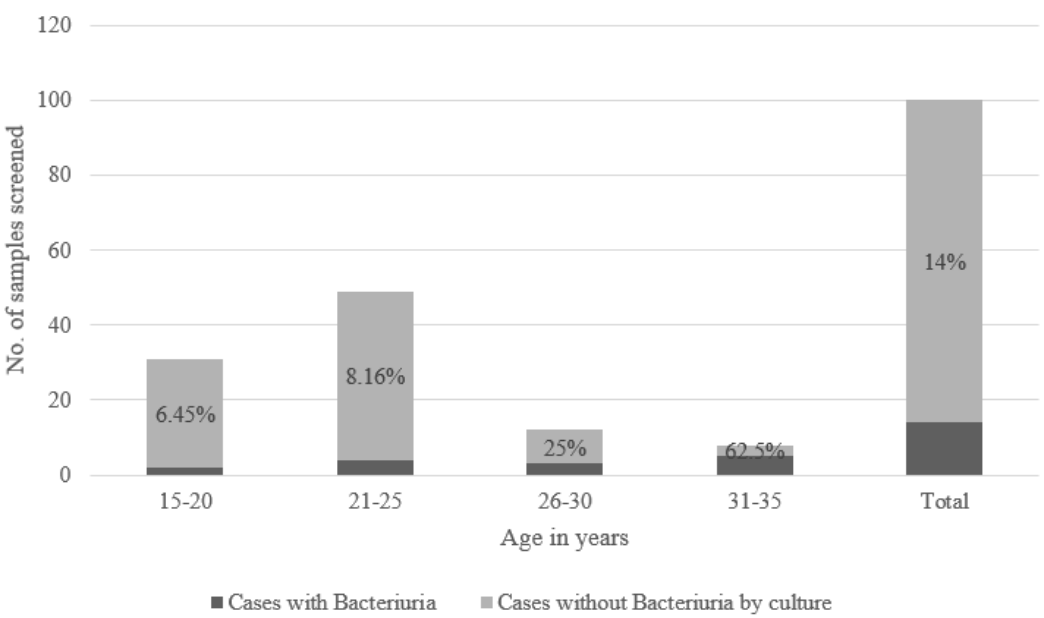

Fig. 1

Fig. 2: Shows correlation between screening tests and culture in detecting gram positive and gram-negative bacteria

Tables 1, 2, 3 and 4 show the performance characteristics of Griess Nitrite, TTC, Catalase test and Gram staining respectively considering culture as gold standard.

Table 1: Griess Nitrite v/s Urine culture

\begin{tabular}{|l|c|c|c|}
\hline \multirow{2}{*}{ Griess Nitrite } & \multicolumn{2}{|c|}{ Urine Culture } & \multirow{2}{*}{ Total } \\
\cline { 2 - 3 } & Positive & Negative & \\
\hline Positive & 6 & 2 & 8 \\
\hline Negative & 8 & 84 & 92 \\
\hline Total & 14 & 86 & 100 \\
\hline
\end{tabular}

Sensitivity $=6 /(6+8) \times 100=42.85 \%$ Specificity $=84 /(2+84) \times 100=97.67 \%$

Table2: TTC v/s Urine culture

\begin{tabular}{|l|c|c|c|}
\hline \multirow{2}{*}{\multicolumn{1}{|c|}{ TTC }} & \multicolumn{2}{c|}{ Urine Culture } & \multirow{2}{*}{ Total } \\
\cline { 2 - 3 } & Positive & Negative & The \\
\hline Positive & 12 & 1 & 13 \\
\hline Negative & 2 & 85 & 87 \\
\hline Total & 14 & 86 & 100 \\
\hline
\end{tabular}

Sensitivity $=12 /(12+2) \times 100=85.71 \%$ Specificity $=85 /(1+85) \times 100=98.83 \%$ 
Table 3: Catalase v/s Urine culture

\begin{tabular}{|l|c|c|c|}
\hline \multirow{2}{*}{ Catalase } & \multicolumn{2}{|c|}{ Urine Culture } & \multirow{2}{*}{ Total } \\
\cline { 2 - 3 } & Positive & Negative & 14 \\
\hline Positive & 12 & 2 & 86 \\
\hline Negative & 2 & 84 & 100 \\
\hline Total & 14 & 86 & \\
\hline
\end{tabular}

Sensitivity $=12 /(12+2) \times 100=85.71 \%$ Specificity $=84 /(2+84) \times 100=97.67 \%$

Table 4: Gram staining v/s Urine culture

\begin{tabular}{|l|c|c|c|}
\hline \multirow{2}{*}{ Gram Staining } & \multicolumn{2}{|c|}{ Urine Culture } & \multirow{2}{*}{ Total } \\
\cline { 2 - 3 } & Positive & Negative & 17 \\
\hline Positive & 13 & 4 & 83 \\
\hline Negative & 1 & 82 & 100 \\
\hline Total & 14 & 86 & \\
\hline
\end{tabular}

Sensitivity $=13 /(13+1) \times 100=92.85 \%$ Specificity $=82 /(4+82) \times 100=95.34 \%$

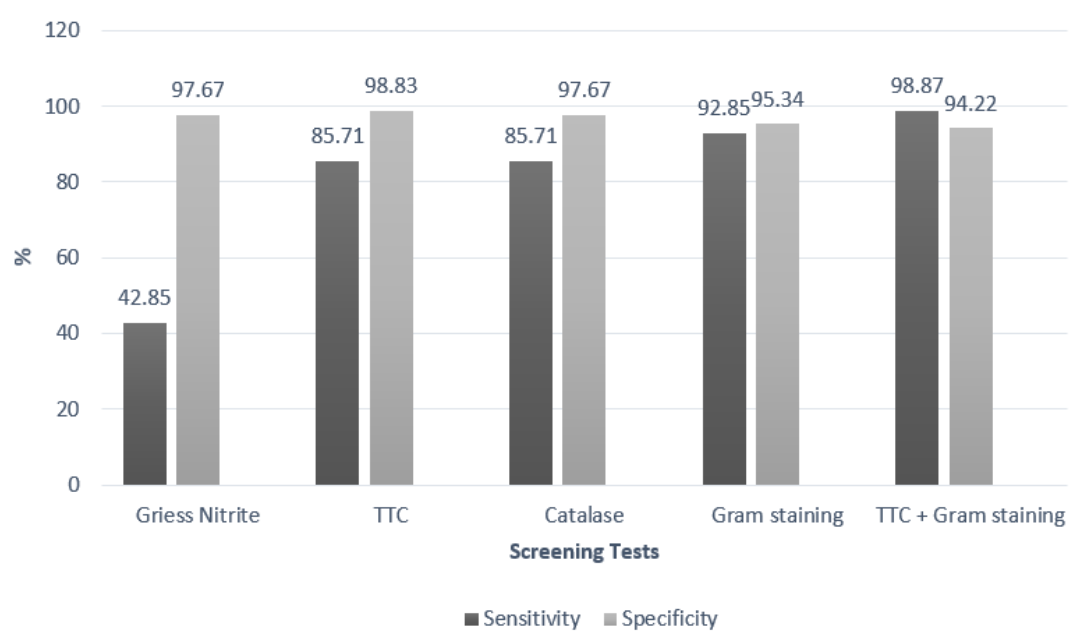

Fig. 3: Gives the comparison of calculated values of sensitivity and specificity of screening tests with culture results

\section{Discussion}

During this study, the asymptomatic bacteriuria was detected in $14 \%$ pregnant women. Hitherto the studies conducted reveal that the prevalence of bacteriuria during pregnancy ranges from $3-12.8 \%$. This variation is related to factors like socioeconomic status of the group of women studied. ${ }^{12,13}$

It was observed that increasing age is associated with a higher frequency of significant bacteriuria ${ }^{[14]}$. In the present study the incidence of bacteriuria in the age group $31-35$ is the highest $62.5 \%$ as compared to other age groups 15-20, 21-25 and 26-30 having incidences of $6.45 \%, 8.16 \%$ and $25 \%$ respectively.

In this study, results of different screening tests like Griess nitrite, TTC, Catalase and Gram staining were compared, urine culture was considered as the gold standard, to reveal the presence or absence of urinary tract infection.

By comparing the culture results with the results of other screening tests the ability of screening tests to detect gram positive and gram-negative bacteria is detected. It is represented in fig. 2 . The cases which were culture negative but still detected as positive by screening tests are mentioned as false positive cases.

On comparison it was found that Gram positive bacteria are not detected by Griess nitrite test because of their inability to reduce nitrate to nitrites.

Results of this study showed that sensitivity and specificity of Griess Nitrite test is $42.85 \%$ and $97.67 \%$ respectively. The observed sensitivity of Nitrite test is low as compared to the study done by Jido et al. who worked on urinary tract infection in pregnant females. Their study results showed that nitrite was $80.9 \%$ sensitive and $57.9 \%$ specific. This variation was seen because nitrite test does not detect organisms unable to reduce nitrate to nitrite, such as Enterococci, Staphylococcus species, Acinetobacter etc. ${ }^{15}$

The sensitivity and specificity of TTC was found to be $85.71 \%$ and $98.83 \%$ respectively. The sensitivity found was greater than the sensitivity found by Dr. 
Nawaz Umar in his study conducted on 500 urine samples collected from pregnant women in Gulbarga, Karnataka. The observed sensitivity of TTC by him was $73.07 \%$. Other workers like Agrawal et al $(81.3 \%)^{16}$ and Wagle et al $(86.9 \%)^{17}$ also noted similar sensitivity of TTC test but low specificity compared to this study.

In this study, Catalase test was found to be $85.71 \%$ sensitive and $97.67 \%$ specific. Similar results were noted by Siddique et al ${ }^{[18]}$. The observed sensitivity of catalase test in a study conducted by Shobha K.L, Amita Shobha Rao, Shilpa K, Ramachandra L was 53\%. Some bacteria such as streptococci which are catalase negative cannot be detected by this test. ${ }^{8}$

This study showed that the sensitivity and specificity of Gram staining are $92.85 \%$ and $95.34 \%$ respectively. The observed sensitivity and specificity of Gram staining in a cross-sectional study conducted on 125 pregnant women by Ajayi $\mathrm{AB}$ et al in Nigeria was $98 \%$ and $74.7 \%$ respectively.

There is variation in results from different studies while comparing performance of different screening tests, it might be because of different sample population or because of variation in procedures while performing the tests.

Based on this study Gram staining has highest sensitivity and TTC has highest specificity. So if we perform these two tests in combination then we get a sensitivity of $98.97 \%$ and specificity of $94.22 \%$ which is not $100 \%$ but very close to it.

\section{Conclusion}

Asymptomatic bacteriuria leading to UTI is the commonly seen condition in pregnancy. And its incidence increases as the age advances. This study showed that the combination of Gram staining and TTC gives nearly $100 \%$ sensitivity and specificity. As these two tests are easy to perform, inexpensive and reagents required for them are easily available, in grass root level laboratories. Where culture facility is not available, the combination of these tests will aid in early diagnosis and commencement of antibiotic therapy which will avert the occurrence of other complications and will also diminish the risk of premature birth and perinatal mortality.

\section{Acknowledgement}

This study was carried out as a short term project approved by the Indian Council of Medical Research to undergraduate students of microbiology.

\section{References}

1. MaClean $A B$ : Urinary tract infection in pregnancy. International Journal of Antimicrobial Agents, 2001;17, 4, 279.

2. Kass EH, (1956): Quoted by Whalley, p. 1967.

3. U.S. Preventive Services Task Force. Guide to clinicalpreventive services: report of the U.S. PreventiveServices Task Force. 2d ed. Baltimore: Williams \&Wilkins, 1996
4. Cunningham FG, Williams JW. Preterm birth. In:Williams obstetrics. 20th ed. Stamford, Conn.:Appleton\& Lange, 1997:797-821.

5. Smaill FM, Vazquez JC. Antibiotics for asymptomatic bacteriuria in pregnancy. Cochrane Database Syst Rev 2007;2:CD000490.

6. Perkins J, Perkins K, Vilke GM, Almazroua FY. Is culturepositive urinary tract infection in febrile children accurately identified by urine dipstick or microanalysis? J Emerg Med 2012;43:1155-9.

7. Mintegi S, Gomez B, Urra E, Romero A, Paniagua N, Lopez E,et al. Use of urine dipstick evaluating young infants with fever without a source and positive urine culture. Pediatr Infect Dis J2011;30:1103-5.

8. Mackie and McCartney. Practical Medical Microbiology. Chapter-4, 14th Edn., Elsevier, 2007: p. 84-85.

9. Weltman O. Griess nitrite test. In: Diagnosis of Urinary Tract Infection. Journal of American Medical Association, 1956; 161: 528 quoted by Schaus R (1956).

10. Simmons and Williams. A simple test for significant bacteriuria. Lancet, 1962; 1:1377.

11. Bailey \& Scott's Diagnostic Microbiology 12th Edition Chapter 57 pg no. 849

12. Turck M, Goffee BS, Petersdorf RG. Bacteriuria of pregnancy - relation to socioeconomic factors. New England Journal of Medicine, 1962;266 (17):857.

13. Kaitz AL, Hodder EW. Method for the detection of significant bacteriuria in large groups of patients. Journal of Clinical Pathology, 1964;17:498 Quoted by Leigh DA and Williams JD.

14. Whalley PJ, Martin FG, Peters PC. Significance of asymptomatic bacteriuria detected during pregnancy. Journal of American Medical Association, 1965;193:879.

15. RangaiahagariA, Nyirabanzi J , Uwizeyimana JP, NgogaE, Wane J.Comparison of urine culture and urine dipstick nitrite test in diagnosis of Urinary Tract Infection. Rwanda Medical Journal2015; Vol.72(1):5-7.

16. Agrawal SK, Das R, Goel M, Kumar M. Tetrazolium reduction test in diagnosis of urinary tract infections. Indian I PatholMicrobiol 1986;29:61-5.

17. Wagle N, Vaidya A, Joshi S, Merchant S. Triphenyl Tetrazolium Chloride (TTC) Dye Test for Quick Diagnosis of Urinary Tract Infection. Indian Journal of Pediatrics1989 sept;Vol56(5):635-38.

18. Siddiqui SM, Deshmukh AB, Afreen U, Bhanap PL. Evaluation of screening tests to detect asymptomatic bacteriuria in obstretic patients at Noor Hospital, Warudi, Jalna. MedPulse - International Medical Journal October 2014;1(10):623-6.

How to cite this article: Waghmare PH, Rudrakshi SS,
Ingole KV, Bawane RS, Shaikh SV. Comparison of
screening tests of asymptomatic bacteriuria in pregnancy
in a Tertiary Care Hospital, Solapur. Indian J Microbiol
Res 2018;5(1):110-114.

